\title{
Six decades of the Society of British Neurological Surgeons
}

\author{
JOHN POTTER \\ Archivist to the Society \\ From the Department of Neurological Surgery, the Radcliffe Infirmary, Oxford, UK
}

The early history of the Society was extensively chronicled by its founding spirit and first secretary, Geoffrey Jefferson, with all the charm and felicity that characterised him and his writings. It is to be found in the handbook issued in 1955 to members of the Society and has been up-dated in subsequent editions by later secretaries: Joe Pennybacker, Patrick Clarke and, most recently, by Alan Richardson. Additional details of the Society's early years may be found in the Cairns Memorial Lecture given by Pennybacker in 1976.

With an annual subscription for full members at nearly fifty times that in 1926, and invested reserves, the Society is entering its seventh decade in an extremely healthy financial state-due to a succession of shrewd and able treasurers. A former president, John O'Connell, who was elected as associate member 50 years ago, has attended the last four celebratory dinners at the Athenaeum. "How was it", he asked at the most recent one, "that our Society came into existence as long ago as 1926? It was because of the imagination and energy of Geoffrey Jefferson who not only organised its foundation but guided its development over some forty years."

The Society, as will be mentioned, was founded as a small scientific club. It is no longer small, the membership having increased some eight-fold. The meaning of the term "scientific" may be debated, but the programmes chosen for meetings, particularly those of the past decade, indicate that the club is at least as scientific as it has ever been, and its members as eager as ever to advance knowledge.

Ours is the second oldest neurosurgical society. The Society of Neurological Surgeons, six years our senior, was formed at the Brigham Hospital, Boston in 1920, and although an early copy of its constitution

Address for reprint requests: John M Potter, DM, FRCS, Department of Neurological Surgery, the Radcliffe Infirmary, Oxford OX2 6HE, UK. exists in our archives, the drafting of our own by Sir Charles Ballance and Geoffrey Jefferson evolved independently. William Osler was tireless in promoting the value of medical societies and associations for the dual purpose of social intercourse and what we would now call continuing education. Osler had influenced Cushing in this matter and, both directly and indirectly, had influenced Jefferson too: through his friendship with the young Jefferson and his wife, and indirectly through the encouragement that Cushing himself gave to the idea of a British Society. But it was as much a small scientific club as a formal society that was desired by those interested in neurosurgery whom Ballance and Jefferson consulted: Percy Sargent, Wilfred Trotter, Bathe Rawling, Donald Armour, James Learmonth and Norman Dott.

$A$ record of the inaugural meeting and the dinner given by Ballance at the Athenaeum on 2 December 1926 occupies the first pages of the Society's original minute book, together with that of the first scientific session at the National Hospital, Queen Square (fig. 1), when Sargent operated on a suprasellar tumour ("no tumour found"), and Armour performed a "cordotomy for gastric crises" and then sought, but also failed to discover, a "presumed acoustic neurofibroma". Such at that time were the uncertainties of exploratory craniotomy.

The particular distinction and prestige of Ballance, who was elected the Society's first president, must have contributed greatly to the respectability of this venture at a time when any serious specialisation, other than in established disciplines such as ophthalmology and Ballance's own interest, aural surgery, was anathema to many surgeons whose stock-intrade was to be Jack of all of them. Admired by Sherrington, contemporary and colleague of Horsley at Queen Square, he had also worked with Cushing. Reproduced here (figs. $2 \& 3$ ) are samples from no 


\section{SOCIETY OF NEUROLOGICAL SURGEONS \\ OF GREAT BRITAIN. \\ eकeकe}

FIRST SCIENTIFIC MEETING

HELD AT THE

\section{NATIONAL HOSPITAL QUEEN SQUARE.}

\section{Friday, December ind, 1926.}

\section{Fig 1}

fewer than twenty-six beautifully hand-written, black-bordered cards sent to Jefferson between October 1926 and November 1927. These, latterly signed simply, "Robin", are a clear testimony to Ballance's energetic role in the creation of the Society, despite the recent death of his wife ("I am so tired and sad that I am quite unfit for anything"). His name recurs even today whenever there is re-consideration of the problem of restoring function to the facial nerve.

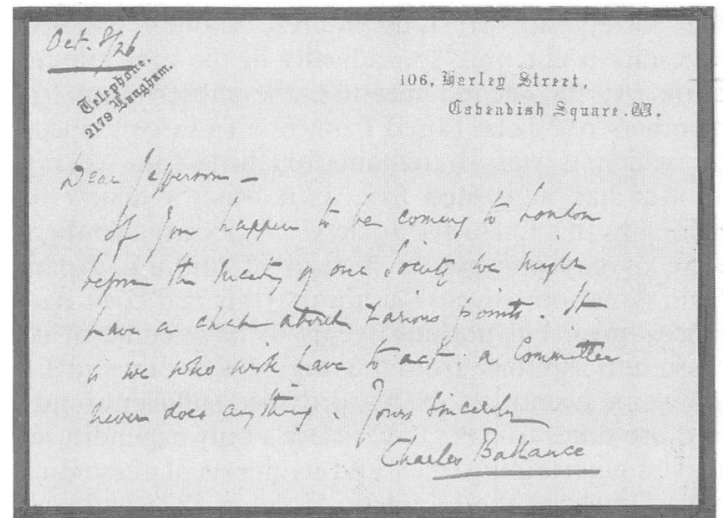

Fig 2
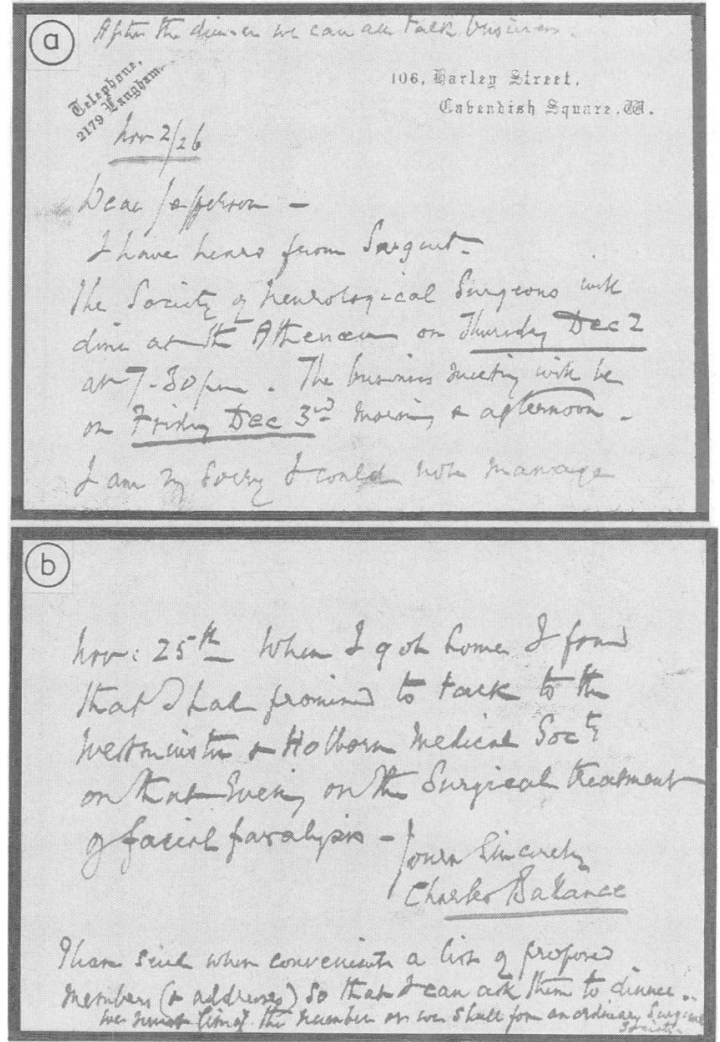

Fig 3

In so short a review as this, an account of the Society's progress may be obtained by selecting, from the seven original source-books of its minutes and from other archival material, some highlights from each of the six decades of its existence. Of necessity these events have been arbitrarily chosen, with the emphasis on those of the earlier years; less need be said about more recent times which are in the memory of those active today.

Meetings during the first (1927-1936) decade were held as they are still, normally twice a year, the earliest being those at the National Hospital, in Manchester, at the London Hospital, in Edinburgh and Oxford. At the third meeting, it had been resolved that the Society should visit from time to time a foreign neurological [sic] clinic, and the first such occasion was in Paris in 1930 under the presidency of Sir Percy Sargent. Instead of papers, there were visits to the clinics of Thomas, de Martel, Alajouanine and Clovis Vincent. Martel operated on an acoustic tumour under local analgesia, in the sitting position, utilising his posterior-fossa boneflap. Operations by the hosts were an important feature of the early meetings, and they contined intermit- 


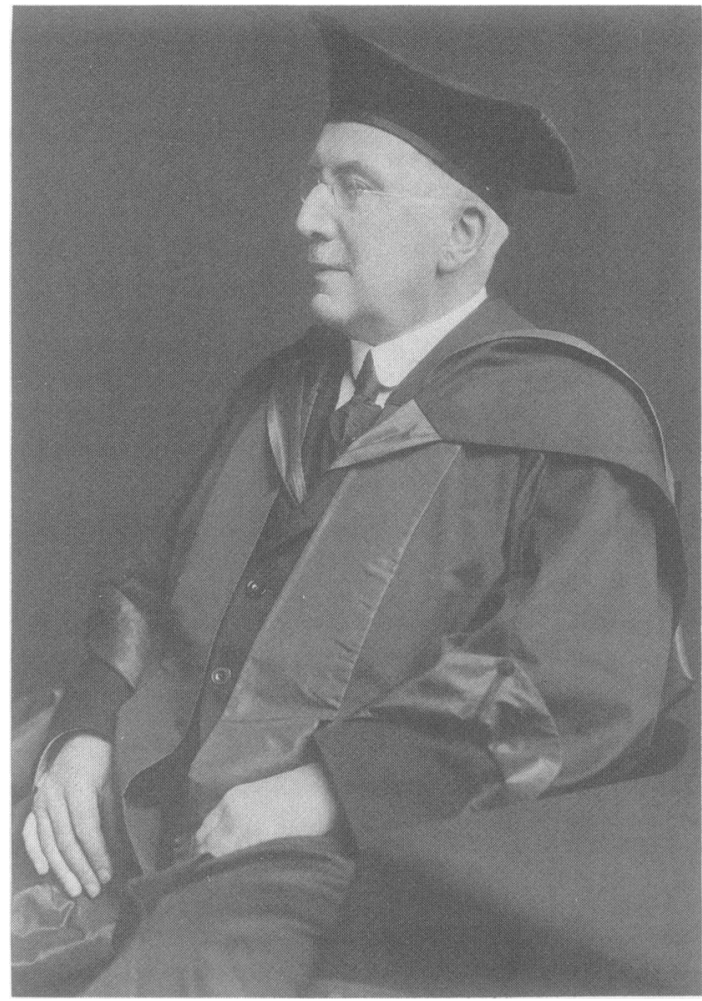

Fig 4 Sir Charles Ballance, the Society's first president

tently later, the last one recorded being at Birmingham in 1950.

The eighteenth meeting, on 3 August 1935 at the National Hospital, was something of a marathon. It was held jointly with the American Neuro-Surgical and the Harvey Cushing Societies while the International Neurological Congress was also in London. Many distinguished American neurosurgeons of the day were present, and others from overseas included Foerster, Moniz, de Martel and Vincent. Jefferson operated at 8.15 am for glossopharyngeal neuralgia, and papers and discussions followed, the last being cut short at 7.20 p.m. so that the gathering could get to Claridges for dinner.

The last meeting of the first ten years was its second to be held in Dublin. Jefferson was now president and the host, Adams McConnell, was to succeed him. McConnell had been a founder member and provided the Society with an Irish dimension which, despite doubts expressed by Ballance as to such a necessity, it cherished greatly and which persists to this day. He is remembered as a generous host to the Society and one of its most ardent supporters during his long life. That meeting was a small gathering of nineteen at which, among other things, positive-contrast ventricu-

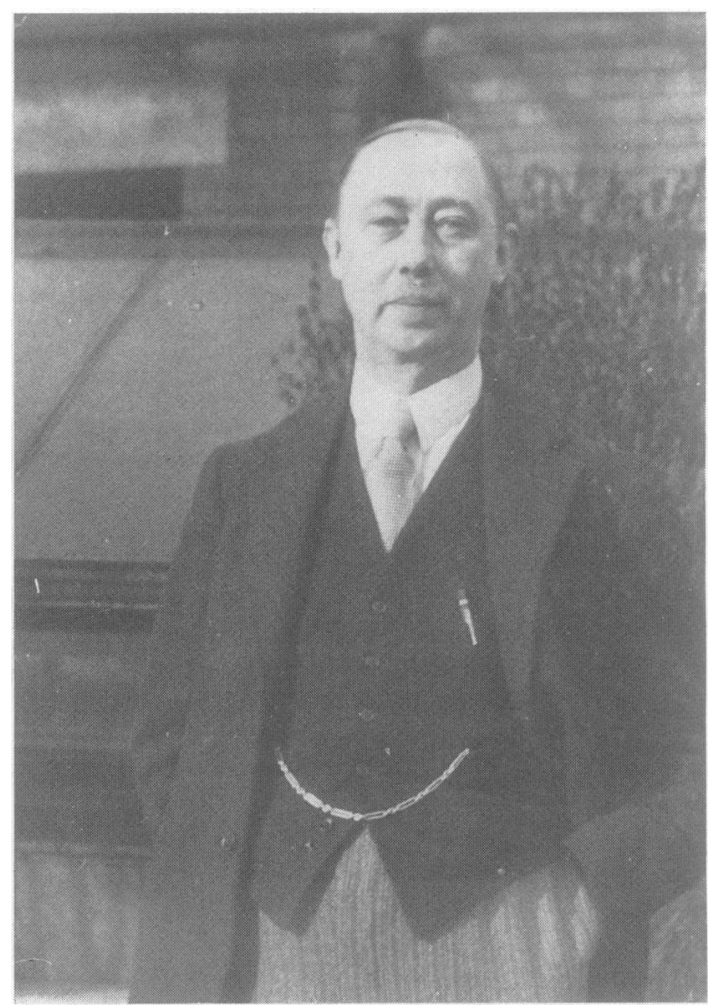

Fig 5 Geoffrey Jefferson, 1938

lography (with Thorotrast) was discussed by James Hardman. At the business meeting, it was resolved that the next meeting should be with Moniz in Lisbon, but this was later amended "owing to the disturbances in Spain". The minutes record that the treasurer, Cecil Wakeley, had reported by letter that the Society's funds showed a balance of $£ 73.3 \mathrm{~s} .8 \mathrm{~d}$, and a pencil note by Jefferson adds, "our money went on free dinners at our banquets". The early finances of the Society are of some interest, though detailed accounts occur only sporadically in the first minute book. At the second meeting, the subscription for members had been raised from one to three guineas (at which it was to remain for thirty-four years); Trotter had suggested five, as it was "a luxury to belong to this Exclusive Society". Associate members were to pay one guinea instead of nothing. Apart from donations towards a library (this had been Ballance's idea, but nothing seems to have come of it) these subscriptions, from the original fifteen members and some twenty associates, provided sufficient funds in those times to meet the Society's only expenditure, that of entertaining itself and its guests at these dinners. Dinner at the Langham Hotel in 1927 had cost 10s.6d. per head (exclusive of wine), and the enter- 
tainment of all those visitors at Claridges was perhaps the cause of "Jeff's" wry note. It was another ten years before it was decided that members should pay for their dinners.

The end of the first decade saw too the death of Ballance, at the age of 80 . In a tribute, included in the Lancet's obituary, Jefferson recalled that the Society's first president had, at the age of 77, journeyed to the Edinburgh and Aberdeen meetings to show films illustrating his work on experimental nerve anastomosis. He had also encouraged from the start our now hallowed tradition, with the words, "the discussion is the important thing". The Society sent a wreath costing two guineas.

The second decade (1937-1946) started with a flourish, but was soon to be overshadowed by the War and the limitations it imposed on the Society's activities; these were nonetheless considerable. At the 21 st meeting in January 1937 at the National Hospital and the Royal College of Surgeons, members had the unusual opportunity "to listen to a report by Lord Dawson and Mr O'Shaughnessy on the selection of cases of coronary occlusion for treatment by surgical means and details of treatment already employed with its experimental basis". (The operation was "cardio-omentopexy", brilliantly pioneered by Laurence O'Shaughnessy, who perished three years later, at the age of 39, during an air raid in Flanders).

In the summer of the same year, there occurred the celebrated German visit: to Tönnis's clinic in Berlin, and to honour Ottfrid Foerster at Breslau. Only three full members were there: McConnell, as president, Dott and Jefferson; there were however fifteen associate, honorary and corresponding members and twenty-two guests. Tönnis and Sauerbruch (O'Shaughnessy's mentor) operated, though on what it is not recorded. Papers included those on cerebral swelling and herniation; on "pseudotumour" (the term had been coined in 1904 by Nonne who was present at the meeting); on the value of arteriography in the diagnosis and treatment of aneurysms; and on the histological variation of astrocytomas. War was then already in the air, and Dickson Wright recalled later how he and Chorobski, returning late to their Berlin hotel and finding pairs of jack boots outside the bedrooms, had mischievously muddled them up and enjoyed the noise and confusion that broke out among their owners early the following morning.

Paris was visited again in 1938, when Dott was elected president. At a Manchester meeting later that year a visitor, T. F. Todd, read a paper on intrathecal alcohol injection for pain; Jefferson removed a huge oligodendroglioma, and there was a discussion on neuro-surgery (the hyphen persisted for many years) in case of war. Cairns provided, in Oxford, the only meeting held in 1939, when Lord Nuffield was the
Society's guest at dinner. This was on the eve of the outbreak of the War, and for its duration a single meeting only was held each year, except in 1943. The first two were again in Oxford, where the Military Hospital for Head Injuries had been established at St. Hugh's College as the centre for neurology and neurosurgery of warfare, and where many subsequent members of the Society were to be found at one time or another. The 1940 meeting ("held under difficult conditions owing to the War") was the first to have its proceedings reported in this Journal (Vol. 3; 343-352, 1940), which also recorded the deaths of Cushing, Trotter, de Martel and Bathe Rawling. Gunshot wounds of the head (Jefferson) brain fungus (Cairns, Ascroft and Hannah), and experimental peripheral nerve injury (J. Z. Young) were now the kinds of topic to be expected at meetings, and these were followed later (in 1941) by "sulphonamide as a local prophylactic in neuro-surgical operations" (Jefferson). The next two meetings were held at Queen Square. Sherrington was present at the first and the subjects included: traumatic paraplegia (Riddoch); intervertebral disc lesions (Botterell, Jackson, O'Connell and Pennybacker); psychiatric assessment of organic brain damage (Dott); the problem, again topical today, of regeneration in the central nervous system (Le Gros Clark); acrylic cranioplasty (Sutcliffe Kerr); and head injuries and crash helmets (Cairns and Holbourne). The thirty-second meeting in November 1944 was at a Canadian Military Hospital near Basingstoke, when military and civilian members discussed mostly battle casualties, and when tantalum cranioplasty (Harold Elliott) was mentioned for the first time at the meetings - as too was penicillin, though only in someone's pencilled notes on one of the programmes; it first appeared formally on a programme at the following meeting, that in June 1945 at Edinburgh.

The second decade closed thankfully in 1946, with the first two meetings of peacetime: at Hill End, St. Albans and at Oxford where there was a re-union with friends of the Society from the United States and, also with those from allied countries in Europe cut off during the War. To the latter the value of penicillin came as a surprise, German propaganda having disparaged it. There were heartfelt comments recorded about the need for political freedom if scientific freedom was to flourish. In an extensive programme, Almeida Lima discussed two hundred leucotomies from Moniz's Clinic; Cairns was re-elected president, and Jefferson again secretary, despite his efforts to relinquish the post. The names of Tönnis, Kobcke and Chiasserini were by unanimous resolution solemnly erased from the Society's membership. (The bitterness expressed by this symbolic act is a part of history which will not now be easily understood; it 
was not formally laid to rest until the successful reunion with the German Society at the joint Cambridge meeting in 1970.)

The meetings of the third decade from 1947 to 1956 , reflected particularly the development of cerebral angiography, aneurysm surgery and "psychosurgery"; as well as the consolidation of antibiotic therapy. There was also the aftermath of brain and spinal injuries sustained during the War. At the Queen Square meeting of 1947, Krynauw reported on hemispherectomy for infantile hemiplegia, and Peter Nathan and Marion Smith were beginning their observations on sensory pathways in the spinal cord. At the Newcastle meeting in 1948, the first signs of the Society's involvement in the world of planning were apparent when a committee was appointed "to consider the terms and conditions of service for neurosurgeons in the Health Service and to send a memorandum to the Central Consultants and Specialists Committee". This was followed by a working party on standard neurosurgical instruments, and advice to the then Ministry of Health on the training and work of speech therapists. Later still, a special committee was to report on the excessive number of senior registrars. In 1950, the full membership was increased from 36 to 50 ; an advisory council was proposed, and this was established two years later.

At the Manchester meeting of 1950, a proposal was received from the Association of British neurologists for a joint meeting. The first was held at Queen Square in February 1952 and deemed a great success. A further five such joint meetings followed during the next seven years; but then none until 1968. The main reason for this was the increasing number of other societies with whom joint meetings seemed desirable, though "opinions were clearly against" a proposal in 1950 from Olivecrona for a European Society.

In 1953, neurosurgical house posts were recognised for pre-registration service at six centres. "Difficulty in obtaining adequate secretarial assistance, and threats of cuts" were "sympathetically discussed" that year, and recorded in the now ever-lengthening minutes; and discussions on the senior registrar establishment (with Dr Godber of the Ministry of Health) continued during the following year. Northfield had by then taken over the secretaryship from Jefferson, whose portrait the Society had commissioned; it was presented to him by Dott at the close of the first day's sessions of the fourth combined meeting with the A.B.N. at the National Hospital in November 1955. It was at that meeting that Sabina Strich introduced us to her view of the pathology of severe traumatic dementia.

The years 1957-66 were those of stereotactic surgery and other treatment for the dyskinesias; temporal lobe epilepsy; cervical spondylosis; shunting for hydrocephalus; hypophysectomy for metastatic breast cancer; and, latterly, aneurysm surgery again. It was also the era of increasing involvement in the politics and planning of the National Health Service, through a survey on the existing neurosurgical services ("glaring discrepancies between one region and another"); inquiries into the staffing structure in hospitals, head injuries, accident services, the training of neurosurgeons and medical education generally; boxing; and the academic status of neurosurgery ("no effective policy emerged"). All in all, there was then much of what is still being discussed 30 years on.

In 1957, the membership was increased to seventy five. By the following year, opposition to a European Congress appeared to be diminishing, the residual reluctance arising chiefly from concern that there would be an increase in the Society's membership subscription which-hardly to be believed todaywas still three guineas, and was not be to be increased (to five-associates, two guineas) until 1961. Membership of the World Federation was however accepted, and the president and secretary were nominated as our delegates. In 1958, Jefferson gave the first of the lectures established in memory of Hugh Cairns, who had died in 1952. A meeting with the Canadian Society was held the following year; and one with the French Society in Edinburgh in 1960 tô् celebrate the opening of the new Edinburgle department and to present Dott with his portrait Pennybacker succeeded Northfield in the secretaryship the same year, and was replaced bs on Small as treasurer. Notable overseas meetings of these- $\overrightarrow{0}$ years were visits to Poland in 1962 and Czechoslovakia in 1964. The decade closed with a 40th anniversary dinner in the same room of the Athenaeum where the Society's inaugural dinner had been held.

The period from 1967 to 1976 saw the arrival of computed tomography; the increasing use of watersoluble myelography; further advances in the surgery of aneurysms; a reactivation of interest in the transethmoidal approach to the region of the sella turcica; and an acceleration of interest in the complexities of increased intracranial pressure. Krayenbuhl's Cairns Lecture (the fifth), at the London Hospital meeting in 1969 , marked the firm establishment of microsurgical techniques. Deliberations on higher training continued throughout these years; problems of manpower and staffing arose again; and there were inquiries about facilities and research. A joint committee of neurological sciences was established to further the interests of the related disciplines, its members later serving also on a neurosciences liaison committee with the DHSS. In 1968 the American Board of Neurological Surgery gave its approval for its trainees to spend a year in any of eleven of our 
centres. At about the same time, our own newly formed specialist advisory committee in neurological surgery held its first meeting, and for a while there followed much discussion within the Society as to what should be its proper functions. Pennybacker retired from the secretaryship in 1969 , and tribute was paid to his long service in that office and previously as treasurer. It was noted that the offices of the Society were becoming "more demanding and important".

During 1969/70 the limit on the membership was again increased, this time from 85 to 100 . Involvement of the younger neurosurgeons in the Society's affairs during this period took a step forward when the senior registrars organised themselves and the Advisory Council held a useful meeting with them to discuss their views on the training that they were receiving. At about the same time, the latest proposals for higher training were received and finally agreed by the Society.

There were two notable events in 1970. At the Spring Meeting in Cambridge, any lingering estrangement from our German colleagues was firmly terminated through a most successful joint meeting with their society. At the Hull meeting in the autumn, Sir Charles Symonds delivered the sixth Cairns lecture and, recalling the breadth of Cairns's vision, put forward a vigorous appeal for closer cooperation between neurology, neurosurgery, and psychiatry. In the following year, there was final agreement to join the European Association of Neurosurgical Societies, our own president, Richard Johnson, himself having been elected president of the Association. In 1972, the Society commissioned a portrait of Joe Pennybacker on his retirement. This recognised not only his outstanding services to the Society but its regret that he had had to decline the presidency for personal reasons. That year, there died at the age of 88 the last of the original members, Adams McConnell.

1973 brought to a Society meeting its first communication on CT scanning, given by J. A. Ambrose at the Southampton meeting. It brought too, from the Cairns trustees, the establishment of a Cairns memorial essay prize. This had followed a characteristic suggestion by Pennybacker that the Cairns lectures (he having been invited to give the next one) might be suspended in favour of such a prize to encourage young neurosurgeons. The first winner was Gordon Brocklehurst, who delivered an abstract of his essay, on the foramen of Magendie, during the meeting at the National Hospital the following year. Now that foreign meetings were becoming so frequent, the Society decided to extend those at home to two days. The membership limit was again raised, for the second time in three years, and was now set at 110 . The subscription too was increased, to $£ 10$ per annum; and a $£ 10$ entrance fee was agreed, though not imposed until three years later. Inflation was now making itself felt, and in 1975 disquiet was being expressed at the size of the registration fees being charged for meetings-particularly by the European Association. The year before, however, there had been a somewhat expensive but nonetheless successful joint meeting in Bermuda, at which the American Association of Neurological Surgeons had marked the occasion by presenting us with a gavel, made by Bronson Ray himself.

By 1975 , the diversity of the Society's activities was such that four sub-committees of the Advisory Council were established: for finance, research, programmes, and current affairs. The last meeting of the fifth decade was the Society's 90 th. It was also its 50th Anniversary and this was duly marked by its president and host in Birmingham, Jack Small: a special badge was struck for the occasion, and souvenir tankards were on sale. The Cairns lecture was reestablished (in addition to the prize essay), and provided the opportunity for the Society to persuade Pennybacker to come from his retirement to deliver it, the seventh in the series, and for him to recall his earliest memories of the Society and its members, and his days with Cairns at the London Hospital. Later in the year, another of the now customary dinners at the Athenaeum celebrated again the Society's 50 years.

The most recent, and sixth decade (1977-1986) has been the most active in the history of the Society, many of its now numerous affairs having achieved considerable complexity. Indeed, the record of these ten years alone has occupied more than two minute books, approximately one book per decade having previously sufficed. This was the era when the long earlier deliberations about higher training, and the functions of the specialist advisory committee, were succeeded by action and the systematic visiting of departments; though discussion about the need for "certification" (later to be termed "accreditation") continued for some time. Agreement was eventually reached that this was desirable and also that senior registrars should keep log books and be interviewed. For overseas trainees the Society decided itself to issue a special certificate of training. In 1982 it was agreed that a representative of the senior registrars should attend business meetings as an observer in order to involve the younger members even more closely in the Society's now extensive deliberations.

Other educational matters have also been prominent during this period. A series of Cairns travelling scholarships was established by the trustees, in addition to the essay prizes and the lectures. Only associate members were eligible, and travel was to be confined to Europe. Discussion on the future of the fellowships of the royal colleges of surgeons continued during the whole decade. "A change towards 
specialisation" was agreed by the Society in 1977 to be desirable, but disagreement as to how best to modify the examinations to this end persisted, not only within the Society but within other specialties too; between the specialties and the royal colleges; and also among the colleges themselves. Since 1984, the Society has maintained its opposition to a three-tier examination, and the retention of a two-part modified FRCS seems now to be the likely outcome. In 1977, the American Board had increased to 18 the number of our centres receiving its recognition.

Four notable Cairns lectures were given during-the decade. The eighth by Iverson emphasised the importance of neurotransmitters; Leksell's son gave the ninth (stereotactic radiosurgery) in place of his father who was ill; du Boulay discussed modern imaging techniques; and the eleventh and most recent was by Blakemore at the Cambridge meeting in April 1986. No consistent policy had been devised for the publication of these lectures; most had been privately printed by the Society for distribution to its members. The general question of increased access to publication, and even the possibility of its own journal, had been discussed by the Society for some time, and continued during these years. Recently, a closer formal link has been negotiated with this journal, whereby the Society's abstracts editor has a place on the editorial board.

On what might be termed, "the political front", the Society has during the past ten years been involved in investigations into "psychosurgery" and brain death, following public anxiety about these matters. Fitness to drive, especially after craniotomy, has been another pre-occupation. In 1982, a neurosciences liaison committee was formed under the auspices of the DHSS, drawing its professional membership from the existing joint neurosciences committee. Notwithstanding these multidisciplinary pressure groups, the decade has closed without any satisfactory solution to the long-standing problem of the provision of neuropathological services. However, following support from the Society over a number of years, the development of a stereotactic radio-surgical unit was achieved and established in Sheffield.

Neurosurgeons are not natural bureaucrats and, following criticism of the sub-committees, that for current affairs was excised in 1977, and those for research and finance combined-this was then itself scrapped the following year, when it was observed that "considerable financial savings had been made by abolishing the sub-committees". These savings had, however, been recognised too late to prevent a doubling of the membership subscription. Further changes in the membership rules were also occurring: in 1979, a new category of "senior member" was devised for those retiring from the NHS, the title "emeritus" having not always been distinguishable in the past from that of "honorary". In 1982, the restriction on the number of full members was removed altogether, and the same year saw the 100th meeting celebrated in Cork in fine Irish style, with Ted Buckley as the host. The following year leads us, through the appointment of an archivist, to the present saga, which now ends with the Society flourishing, in excellent shape, and already looking to the next century, if not yet to its centenary. 